RESEARCH REPORT

\title{
Low socioeconomic status of the opposite sex is a risk factor for middle aged mortality
}

\author{
Maria S Kopp, Árpád Skrabski, Ichiro Kawachi, Nancy E Adler
}

J Epidemiol Community Health 2005;59:675-678. doi: 10.1136/jech.2004.027284

\begin{abstract}
See end of article for authors' affiliations

.....................

Correspondence to: Dr M S Kopp, Institute of Behavioural Sciences, Semmelweis University of Medicine, Hungary; kopmar@net.sote.hu

Accepted for publication 6 April 2005
\end{abstract}

\begin{abstract}
Objectives: To examine the relations between subjective social status, and objective socioeconomic status (as measured by income and education) in relation to male/female middle aged mortality rates across 150 sub-regions in Hungary.

Design: Cross sectional, ecological analyses.

Setting: 150 sub-regions of Hungary.

Participants and methods: 12643 people were interviewed in the Hungarostudy 2002 survey, representing the Hungarian population according to sex, age, and sub-regions. Independent variables were subjective social status, personal income, and education.

Main outcome measure: For ecological analyses, sex specific mortality rates were calculated for the middle aged population (45-64 years) in the 150 sub-regions of Hungary.

Results: In ecological analyses, education and subjective social status of women were more significantly associated with middle aged male mortality, than were male education, male subjective social status, and income. Among the socioeconomic factors female education was the most important protective factor of male mid-aged mortality. Subjective social status of the opposite sex was significantly associated with midaged mortality, more among men than among women.

Conclusion: Pronounced sex interactions were found in the relations of education, subjective social status, and middle aged mortality rates. Men seem to be more vulnerable to the socioeconomic status of women than women to the effects of socioeconomic status of men. Subjective social status of women was an important predictor of mortality among middle aged men as was female education. The results suggest that improved socioeconomic status of women is protective for male health as well as for female health.
\end{abstract}

西 $\mathrm{n}$ the past decade possibly the most important observation in "new public health" was that relative socioeconomic disadvantage constitutes a basic health risk in society. If morbidity and mortality data are corrected with the traditional risk factors, relative social disadvantage has a far greater effect than the other factors. ${ }^{12}$ The surveys of Marmot and coworkers ${ }^{2-6}$ conducted among English civil servants showed that their level of employment is in close and inverse relation with their mortality rates, just as with the occurrence of cardiovascular diseases and chronic non-specific respiratory disorders. Men were found to be more susceptible to the effects of relative income inequality and GDP deprivation, but the pathway of this relation is yet to be explained. ${ }^{4}$ Kaplan et $\mathrm{al}^{78}$ and Kawachi and coworkers ${ }^{9-11}$ arrived at the same conclusions concerning the United States of America. According to our knowledge there have been no studies analysing the association between socioeconomic status (SES) of the opposite sex and mortality rates.

One of the most interesting features of the so called Central-Eastern European health paradox is the sex difference in worsening mortality despite the fact that men and women share the same socioeconomic and political circumstances. Up to the end of the 1970s, mortality rates in Hungary were lower than those seen in Great Britain or Austria. Subsequently, mortality rates declined in Western Europe. But in Hungary and in other Central-Eastern European countries this trend was reversed, especially among middle aged men. In the late 1980s, the mortality rates among 45-64 year old men in Hungary rose to and remained at levels that were higher than they were in the 1930s, while there was not such an increase among women. ${ }^{12-16}$ The main causes of premature mortality are cardiovascular and oncological disorders both among men and women in about
$75 \%$ of cases. Alcohol related (hepatic chirrosis) and suicide mortality is also much higher in Hungary, more so among men than among women. In Hungarian men below 65 years of age, the standardised mortality rates are 2.4 times higher than the European average, among women the standardised mortality rates are 1.9 times higher. ${ }^{17}$ The mortality ratio comparing the lowest with highest educational stratum is 1.8 for Hungarian men, compared with 1.2 for women. ${ }^{18}$ Within Hungary, there are considerable sex differences in 45-64 years old mortality among the 150 Hungarian subregions. ${ }^{12} 1319$

According to our earlier papers, socioeconomic disparities are important determinants of mortality, but psychosocial factors such as depression, vital exhaustion, no meaning in life, and social mistrust are also of great importance. ${ }^{12-16}$ In a recent study we analysed the associations of self rated health and social standing on premature male and female mortality on the 20 county level of Hungary, and we found a strong interrelation between male and female social status, subjective evaluation of health and mid-aged mortality rates. ${ }^{20}$ Because the county level is an aggregate of several subregions the purpose of this study was to analyse the opposite sex interaction on a much more detailed level with the help of the data of the 150 sub-regions of Hungary. Here we concentrated on the association between male and female objective and subjective SES and mid-aged mortality differences among these sub-regions of Hungary. In this study our main question was the association of the SES of the opposite sex on the premature mortality of men and women.

Abbreviations: SES, socioeconomic status; SSS, subjective social status 
Table 1 Descriptive statistics of the male and female socioeconomic characteristics in the 150 Hungarian sub-regions according to Hungarostudy 2002 (sub-regional average, minimal, maximal values, and standard deviations)

\begin{tabular}{lllll}
\hline & Mean & SD & Minimum & Maximum \\
\hline Male education & 3.28 & 0.36 & 2.30 & 4.31 \\
Female education & 3.20 & 0.45 & 2.33 & 4.93 \\
Male income & 1.62 & 0.26 & 1.05 & 2.83 \\
Female income & 1.30 & 0.17 & 0.97 & 1.91 \\
Male SSS & 3.88 & 0.48 & 2.41 & 5.25 \\
Female SSS & 3.74 & 0.52 & 2.10 & 5.14 \\
\hline
\end{tabular}

\section{METHODS}

The Hungarostudy 2002 is a national cross sectional survey representing the Hungarian population over the age of 18 residing in the 150 sub-regions of Hungary. In 2002, 12643 persons were interviewed in their homes. ${ }^{12} 13$

\section{Sampling methods}

A clustered, stratified sampling procedure was implemented. The sample represented $0.16 \%$ of the population above age 18 according to age, sex, and regions. The sampling frame was the National Population Register. The refusal rate was $17.7 \% .^{12} 13$

\section{Measures of objective and subjective social status (SSS) and mid-aged mortality}

SSS was measured by the 10 rungs ladder scale developed by Adler et al. ${ }^{21}$ This measure allows respondents to place themselves in relation to those best and worst off in terms of income, education, and occupation in the country. These rankings have been shown to relate to health status at the individual level. ${ }^{21}{ }^{22}$ We further included the following socioeconomic variables: education measured by the highest educational grade on a six level scale (from less than primary to university level) and personal income, with the help of a separate card showing eight categories (from 50000 forints or less to 500000 forints or more per month). For ecological analyses, the average values for the above variables were computed for the 150 Hungarian sub-regions.

Male and female mortality rates in the 45-64 years age group were obtained for each sub-region from the Central Statistical Office sub-regional data base (CSO). ${ }^{19}$

\section{Statistical methods}

SPSS (1999) base 9 was used for all analyses. Pearson's correlation analyses, and multiple stepwise linear regression analyses with entry 0.05 , removal 0.10 for probability of $F$ were used. For the ecological analyses, the average values of education, personal income, and SSS were computed for each of the 150 Hungarian sub-regions, separately for men and women, and then correlated with mid-aged mortality rates for each of these sub-regions.

The research was approved by the ethics committee of the Semmelweis University, Budapest and conforms to the principles embodied in the Declaration of Helsinki.

\section{RESULTS}

\section{Relation between objective and SSS and male and female middle aged mortality rates}

Table 1 shows the minimal, maximal, and mean values of the analysed socioeconomic variables in the 150 sub-regions of Hungary. Education is almost equal in Hungary among women and among men, but with higher variance among women. The maximal value of female education is much higher in some regions showing a real development. Despite this fact average personal income of women is considerably lower compared with men with lower variances. Interestingly the SSS of women is similar to male subjective social status, which shows that in female subjective standing the overall situation of the family might be a more important factor than in the individual SSS of women.

For the purpose of ecological analysis we first computed the correlation coefficients for the average levels of variables in the 150 sub-regions of Hungary. Table 2 shows that among men middle aged male mortality showed significant correlations with male education, income, and subjective social status, but in each case female SES variables showed closer connections with male mid-aged mortality than did the male SES variables. Female SSS, income, and education were correlated with female mortality. Male SSS and education related to female mortality, but male income did not.

Table 3 shows the results of ecological multivariate stepwise regressions models in connection with male midaged mortality. Model 1, which includes only male variables, shows that male education explained $11.5 \%$ of male mortality differences among sub-regions, while income and SSS were no longer significant. Interestingly the female SES variables alone in model 2 explained comparatively more of the variance of male premature mortality $(28.1 \%)$. When examined together in model 3, female SSS was a more

Table 2 Pearson correlations for male and female mid-aged (45-64 years old) mortality and socioeconomic status variables in the 150 sub-regions of Hungary $(n=150)$

\begin{tabular}{lllll}
\hline & $\begin{array}{l}\text { Middle age (45-64 } \\
\text { year) male mortality }\end{array}$ & $\begin{array}{l}\text { Significance } \\
\text { (two tailed) }\end{array}$ & $\begin{array}{l}\text { Middle age (45-64 year) } \\
\text { female mortality }\end{array}$ & $\begin{array}{l}\text { Significance } \\
\text { (two tailed) }\end{array}$ \\
\hline Male SSS & -0.165 & 0.044 & -0.220 & 0.007 \\
Male income & -0.173 & 0.034 & $\mathrm{NS}$ & 0.069 \\
Male education & -0.348 & 0.000 & -0.274 & 0.001 \\
Female SSS & -0.306 & 0.000 & -0.229 & 0.005 \\
Female income & -0.329 & 0.000 & -0.266 & 0.001 \\
Female education & -0.521 & 0.000 & -0.310 & 0.000 \\
\hline
\end{tabular}


Table 3 Ecological level multivariable linear regression results for middle aged (45-64 years old) male mortality in the 150 sub-regions of Hungary $(n=150)$

\begin{tabular}{|c|c|c|c|c|c|}
\hline & $\boldsymbol{\beta}$ & SE & $t$ & $\mathbf{p}$ & Adjusted $R^{2}$ \\
\hline \multicolumn{6}{|l|}{ Model 1 With male SES variables } \\
\hline Constant & 149.5 & 9.8 & 15.3 & .000 & 11.5 \\
\hline $\begin{array}{l}\text { Male education } \\
\text { Excluded variables: male income and male SSS } \\
\text { Model } 2 \text { With female SES variables }\end{array}$ & -13.4 & 2.9 & -4.5 & .000 & \\
\hline Constant & 167.4 & 8.5 & 19.7 & 0.000 & \\
\hline Female education & -14.6 & 2.3 & -6.4 & 0.000 & 26.6 \\
\hline $\begin{array}{l}\text { Female SSS } \\
\text { Excluded variable: female income }\end{array}$ & -4.0 & 1.9 & -2.0 & 0.045 & 28.1 \\
\hline \multicolumn{6}{|l|}{ Model 3 With male and female SES variables } \\
\hline Constant & 167.4 & 8.5 & 19.7 & 0.000 & \\
\hline Female education & -14.6 & 2.3 & -6.4 & 0.000 & 26.6 \\
\hline Female SSS & & & & 0.045 & 28.1 \\
\hline $\begin{array}{l}\text { Excluded variables: male education, male income, } \\
\text { male SSS, female income }\end{array}$ & & & & & \\
\hline
\end{tabular}

significant predictor of male mortality than male SSS; female education, and subjective social standing explained the midaged mortality differences among the sub-regions, while the male SES characteristics were excluded from the model.

Among women, ecological regression models showed weaker associations (table 4) with female variables. Female education explained only $9 \%$ of the variance in female midaged mortality and income and SSS were excluded. Male SES factors were even weaker predictors of female mortality, with male education explaining $6.9 \%$ of female mortality rate variation. This is much weaker than the opposite association between female SES and male mortality. With both male and female SES variables included, female education and male SSS together explained $11.1 \%$ of the mid-aged female mortality differences among sub-regions.

\section{DISCUSSION}

Our paper analysed ecological level data from a large, representative survey of the Hungarian population. Our main question was the association of the SES of the opposite sex on the premature mortality of men and women.

In agreement with our earlier results, ${ }^{1520}$ there is an interrelation of male and female health within regions. Male health seems to be highly vulnerable to SES and its subjective perception by women. Interestingly high educational level of women in a sub-region was an important protective factor for men; this may mean that the improvement of SES of women is good for male health as well. Women's health seems to be less susceptible to their own objective and subjective socioeconomic situation and to the SES of men. This difference might contribute to the fact that middle aged women experienced less health deterioration during the recent economic transition despite sharing the same socioeconomic and political circumstances as men. ${ }^{20}$

Although education and income were significant predictors of mortality both among men and women, subjective social standing was also strongly associated with mid-aged mortality. These results are in good agreement with the latest results of the Whitehall II study, which shows SSS reflects the cognitive averaging of a broad set of markers of SES situation including but not limited to education and occupation..$^{22}$

The SSS and education of women were strongly and inversely correlated with male mid-aged mortality, which means that in sub-regions where women hold more negative appraisal of the social standing and have lower education, there is greater male health deterioration.

SES was assessed both among men and women on the basis of their overall evaluation of their social standing, and the ecological aggregates of these measures were analysed on regional level for men and women. Today unemployment is higher among men than among women in Hungary, the normal model is the two person household. ${ }^{23}$ Despite the high educational level of women, the average female income of women is much lower. It can be hypothesised that women assess their subjective social standing according to the overall situation of the family.

These results suggest that at least in a more traditional society such as in Hungary, in the period of intense sociopolitical changes middle aged men are more vulnerable to the

Table 4 Ecological level multivariable linear regression results for middle aged (45-64 years old) female mortality in the 150 sub-regions of Hungary $(n=150)$

\begin{tabular}{|c|c|c|c|c|c|}
\hline & $\beta$ & SE & $t$ & $\mathbf{p}$ & Adjusted $R^{2}$ \\
\hline \multicolumn{6}{|l|}{ Model I With female SES variables } \\
\hline Constant & 51.4 & 2.8 & 18.2 & 0.000 & \\
\hline Female education & -3.5 & 0.87 & -4.0 & 0.000 & 9.0 \\
\hline \multicolumn{6}{|c|}{$\begin{array}{l}\text { Excluded variables: female income and female SSS } \\
\text { Model } 2 \text { With male SES variables }\end{array}$} \\
\hline Constant & 52.7 & 3.6 & 14.6 & 0.000 & \\
\hline $\begin{array}{l}\text { Male education } \\
\text { Excluded variables: male SSS and male income }\end{array}$ & -3.8 & 1.1 & -3.5 & $\begin{array}{l}0.001 \\
0.000\end{array}$ & 6.9 \\
\hline Model 3 With male and female SES variables & & & & 0.035 & \\
\hline Constant & 57.0 & 3.86 & 14.768 & 0.000 & \\
\hline Female education & -3.117 & 0.880 & -3.540 & 0.001 & 9.0 \\
\hline Male SSS & -1.747 & 0.824 & -2.119 & 0.036 & 11.1 \\
\hline $\begin{array}{l}\text { Excluded variables: male education and income, } \\
\text { female income and SSS }\end{array}$ & & & & & \\
\hline
\end{tabular}




\section{What is already known about this topic}

- There is a strong social gradient in mid-aged mortality

- Men are more susceptible to income inequality than women

- Subjective social status is a strong predictor of health

\section{What this study adds}

- The socioeconomic status of the opposite sex was a significant predictor of mid-aged mortality, more among men than among women

- Befter education of women was a significant protective factor for male mid-aged mortality

- Subjective social status of the opposite sex was a significant predictor of mid-aged mortality, much more among men than among women

- Improved socioeconomic status of women is protective for male health

\section{Summary of policy implications}

In both sexes, education and subjective social status are significantly connected with the premature mortality rates of the opposite sex as well. Education and the subjective social status of women is significantly associated with male midaged mortality. Consequently in preventing the high male premature mortality in Central-Eastern Europe women might play an important part. The improvement of higher education of women seems to be beneficial both for male and female longevity. Educated women accept more the responsibility for the socioeconomic situation of their family. The feeling of relative socioeconomic deprivation among women in the comparatively deprived regions, in contrast, might result in a vicious cycle of relative deprivation among men.

socioeconomic risks of their society. They are affected not only by their own social situation but by the subjective evaluation of social status of women as well. In preventing the high male premature mortality in Central-Eastern Europe women might play an important part.

It can be hypothesised that the socio-political changes may have different consequences for men and women. The improvement of higher education of women seems to be beneficial both for male and female longevity. Educated women accept more the responsibility for the socioeconomic situation of their family. The feeling of relative socioeconomic deprivation among women in the comparatively deprived regions, in contrast, might result in a vicious cycle of relative deprivation among men.

\section{ACKNOWLEDGEMENTS}

The authors thank the other members of the "Hungarostudy 2002" team (János Réthelyi, Adrienne Stauder, Csilla Csoboth, György Gyukits, János Lőke, Andrea Ódor, Katalin Hajdu, Csilla Raduch, András Székely, László Szűcs, Sándor Rózsa), to the network of district nurses for the home interviews, for Professor András Klinger for the sampling procedure, for the National Population Register for the selection of the sample, and to the John D and Catherine T MacArthur Foundation Research Network on Socioeconomic Status and Health.

\section{Authors' affiliations}

M S Kopp, Á Skrabski, Institute of Behavioural Sciences, Semmelweis University of Medicine, Hungary

I Kawachi, Department of Health and Social Behavior, Harvard School of Public Health, Boston, USA

N E Adler, Center for Health and Community, University of California, San Francisco, USA

Funding: this study was supported by the United Nation Development Program (UNDP) project no HUN/00/002/A/01/99, and the National Research Fund (OTKA) projects No T-32974 (2000), OTKA TS-40889 (2002) and TS-049785 (2004) Scientific School grants and NKFP 1/ $002 / 2001$ and NKFP $1 \mathrm{~b} / 020 / 2004$.

Conflicts of interest: none declared.

\section{REFERENCES}

1 Wilkinson RG. Health, civic society in Eastern Europe before 1989. In: Hertzman C, ed. Environmental and non-environmental determinants of the East-West life expectancy gap. Amsterdam: Kluwer, 1996.

2 Marmot MG. The status syndrome, how social standing affects our health and longevity. New York: Henry Holt, 2004.

3 Marmot MG. The social pattern of health and disease. In: Blane D, Brunner E, Wilkinson R, eds. Health and social organization. London: Routledge, 1996:42-70.

4 Marmot M, Wilkinson R. Social determinants of health. Oxford: Oxford University Press, 1999.

5 Marmot MG, Kogevinas M, Elston MA. Social/economic status and disease. Annu Rev Public Health 1987;8:111-35.

6 Marmot MG, Davey Smith G, Stansfeld S, et al. Health inequalities among British servants: the Whitehall II study. Lancet 1991;337:1387-93.

7 Kaplan GA, Pamuk ER, Lynch JW, et al. Inequality in income and mortality in the United States: analysis of mortality and potential pathways. BMJ 1996;312:999-1003.

8 Kaplan GA. Where do shared pathways lead? Psychosom Med 1995;57:208.

9 Kawachi I, Berkman LF. Social cohesion, social capital, and health. In: Berkman LF, Kawachi I, eds. Social epidemiology. New York: Oxford University Press, 2000.

10 Kawachi I, Kennedy BP. Health and social cohesion: why care about income inequality? BMJ 1997;314:1037-40.

11 Kawachi I, Kennedy BP, Lochner K, et al. Social capital, income inequality, and mortality. Am J Public Health 1997;87:1491-8.

12 Skrabski A, Kopp MS, Rózsa S, et al. Life meaning: and important correlate of health in the Hungarian population. Int J Behav Med 2005; 12:78-85.

13 Skrabski Á, Kopp MS, Kawachi I. Social capital and collective efficacy in Hungary: cross sectional associations with middle aged female and male mortality rates. J Epidemiol Community Health 2004;58:340-5.

14 Kopp MS, Réthelyi J. Where psychology meets physiology: chronic stress and premature mortality - the Central-Eastern-European health paradox. Brain Res Bull 2004;62:351-67.

15 Skrabski Á, Kopp MS, Kawachi I. Social capital in a changing society: cross sectional associations with middle aged female and male mortality rates. J Epidemiol Community Health 2003;57:114-19.

16 Kopp MS, Skrabski Á, Szedmák S. Psychological risk factors, inequality and self-rated morbidity in a changing society. Soc Sci Med 2000;51:1350-61.

17 Gárdos É. Health status of population. Budapest: Central Statistical Office, 2002.

18 Mackenbach JP, Kunst A, Groenhof F, et al. Socioeconomic inequalities in mortality among women and among men: an international study. Am J Public Health 1999;89:1800-8.

19 Statistical Office. Central Statistical Office Data Base for Sub-regions of Hungary in 1996-2000. Budapest: Statistical Office, 2003.

20 Kopp M, Skrabski Á, Réthelyi J, et al. Self-rated health, subjective social status, and middle-aged mortality in a changing society. Behav Med 2004;30:65-70.

21 Adler NE, Epel ES, Castelazzo G, et al. Relationship of subjective and objective social status with psychological and physiological functioning: preliminary data in healthy women. Health Psychol 2000;19:586-92.

22 Singh-Manoux A, Adler NE, Marmot M. Subjective social status: its determinants and its association with measures of ill-health in the Whitehall II study. Soc Sci Med 2003;56:1321-33.

23 Central Statistical Office. Men and women in Hungary. Budapest: Central Statistical Office, 2003. 